\title{
METODOLOGIAS PARTICIPATIVAS E EDUCAÇÃO PERMANENTE NA FORMAÇÃO DE AGENTES COMUNITÁRIOS/AS DE SAÚDE
}

\author{
PARTICIPATORY METHODOLOGIES AND PERMANENT EDUCATION IN TRAINING COMMUNITY/HEALTH \\ AGENTS
}

\author{
METODOLOGÍAS PARTICIPATIVAS Y EDUCACIÓN PERMANENTE EN LA FORMACIÓN DE AGENTES \\ COMUNITARIOS DE SALUD
}

\author{
Natália Hosana Nunes Rocha ${ }^{1}$ \\ Paula Dias Bevilacqua ${ }^{2}$ \\ Marisa Barletto ${ }^{3}$
}

Resumo Busca-se neste texto refletir sobre o uso de metodologias participativas na educação permanente de agentes comunitários/as de saúde, numa discussão sobre os limites e potencialidades de tais metodologias estimularem reflexões e possíveis mudanças nas práticas cotidianas desses profissionais. Foram realizadas entrevistas e caminhadas transversais com os/as agentes, que resultaram em relatorias utilizadas como material de análise. Não seria simples mensurar o impacto que essa metodologia tem no processo de construção do pensamento reflexivo, mas a análise do potencial das metodologias participativas em atividades de formação de agentes comunitários da saúde permitiu perceber que houve empoderamento quanto aos temas abordados. Pôde-se compreender o quão significativas as metodologias se mostraram na abordagem das temáticas, especialmente nos temas 'prevenção de doença e promoção da saúde' e 'violência de gênero'. Conclui-se que o fato de algo poder ser percebido com outros significados e sentidos possibilita outros modos da produção de práticas cotidianas.

Palavras-chave construção coletiva; conhecimento e prática; atuação profissional.
Abstract This article seeks to reflect on the use of participatory methodologies in the continuing education of community/health workers, in a discussion about the limits and possibilities of such methodologies, encouraging reflections and possible changes in these professionals' daily practices. Transect interviews and walks were carried out with the agents, which resulted in the rapporteurs that used as material for analyses. It would be no simple task to measure the impact that this methodology has on the process of building reflective thought, but the analysis of the potential of participatory methodologies in the training activities aimed at community health workers allowed us to realize that there was empowerment with regard to the themes addressed. It was possible to understand how significant the methodologies have shown to be in addressing the issues, especially with regard to the 'prevention of disease and promotion of health' and to 'gender violence.' In sum, the fact that something can be realized with other meanings and senses allows other modes of production of daily practices.

Keywords collective construction; knowledge and practice; professional performance. 


\section{Introdução}

De acordo com o Ministério da Saúde, a implementação do Programa Saúde da Família (PSF) se mostrou uma importante conquista para os serviços de atenção primária na política de saúde brasileira, visando melhorar a qualidade de vida da população e educar para a saúde. O PSF, “surgido em 1994 e inicialmente voltado para estender a cobertura assistencial em áreas de maior risco social, aos poucos adquiriu centralidade na agenda governamental" (Escorel et al., 2007, p. 165). No ano de 1998, o PSF passou a ser considerado como Estratégia Saúde da Família (ESF), visando à reorientação do modelo assistencial e à modificação da dinâmica dos serviços e ações de saúde dos sistemas municipais. Segundo esses autores, a intenção dessa reorientação foi fazer com que a unidade de saúde da família se mostrasse como "a porta de entrada ao sistema local e o primeiro nível de atenção, o que supõe a integração à rede de serviços mais complexos" (Escorel et al., 2007, p. 165).

As equipes da ESF são compostas por, no mínimo, um médico, um auxiliar de enfermagem, um enfermeiro e seis agentes comunitários de saúde (ACSs). Quando ampliadas, as equipes contam ainda com um dentista, um auxiliar de consultório dentário e um técnico em higiene dental. Esse/a profissional, o/a ACS, surge como figura de destaque, já que para exercer suas funções é exigido que resida no bairro de atuação da equipe, a fim de estabelecer o vínculo entre comunidade/usuário e equipe de saúde da família, fazendo o intermédio entre o conhecimento científico, discurso biomédico e o saber do senso comum/popular.

Como os/as ACSs estão em contato direto com a população, torna-se necessária sua formação e capacitação para que possam transformar suas práticas de trabalho, objetivando melhorias da qualidade dos serviços de saúde e fundamentação para desenvolverem um contínuo trabalho de conscientização com a comunidade no que se refere a questões ligadas à saúde. Os/as ACSs exercem a função de mobilizadores/as sociais, intermediando e construindo saberes no exercício cotidiano de sua prática profissional/cidadã em contato direto com a comunidade. Por tais especificidades, afirma-se que o/a agente comunitário/a é o elo entre a equipe de saúde e a comunidade.

Pensando na formação dos/as profissionais da saúde, o que incluía os/as ACSs, a educação permanente em saúde (EPS) foi adotada como ação estratégica para operacionalização da Política de Educação e Desenvolvimento para o Sistema Único de Saúde - SUS (Brasil, 2009). A EPS parte do pressuposto da aprendizagem significativa, que promove e produz sentidos, sugerindo que a prática profissional deva ser baseada na reflexão crítica da realidade. Assim, a EPS é a realização do encontro entre o mundo de formação e o mundo do trabalho, onde o aprender e o ensinar se incorporam ao cotidiano 
das organizações e ao trabalho. A EPS consiste na transformação do processo de trabalho dos/as profissionais da saúde, visando a melhorias na qualidade dos serviços prestados à população, ou seja, como um processo de constante aperfeiçoamento, pelos/as profissionais da saúde, de suas técnicas de acordo com a demanda (Ribeiro e Motta, 1996).

Segundo Mancia, Cabral e Koerich (2004, p. 606), a “educação permanente estrutura-se a partir de dois elementos: as necessidades do processo de trabalho e o processo crítico como inclusivo ao trabalho". Então, a EPS objetiva tornar o serviço de saúde pública uma rede de ensino-aprendizagem no exercício do trabalho, na área de saberes e prática em saúde, para que esse setor venha a ser um local de atuação composto por profissionais críticos/as, reflexivos/as de sua prática, comprometidos/as com o trabalho e competentes (Ceccim, 2005).

Tendo em vista que a educação é definida como um mecanismo de modificação das pessoas, devem-se adotar métodos e práticas que possam reconhecer o sujeito em sua totalidade, em sua dimensão individual, na esfera social e cultural, levando em conta sua identidade e as experiências que traz consigo para que possa haver um aprendizado significativo (Zacarias, 2005 apud De Castro Dias, 2007, p. 2).

Para tanto, as metodologias participativas se mostram bastante relevantes, pois têm como pressuposto que o processo de aprendizagem surge da interação dos sujeitos, seus sentimentos, atitudes, crenças, costumes e ações. Considerando e integrando a subjetividade no processo educativo, tais metodologias estimulam a reflexão sobre a realidade e reorientam posturas, atos e opiniões a partir da visão crítica da realidade cotidiana na qual os sujeitos estão inseridos. Segundo Weitzman (2008), quando utilizamos o termo metodologias participativas, pretendemos fazer referência aos métodos empregados no modelo de educação popular idealizado por Paulo Freire.

Na cidade de Viçosa, no estado de Minas Gerais, o Núcleo Interdisciplinar de Estudos de Gênero da Universidade Federal de Viçosa (NIEG/UFV) vem realizando trabalhos em educação permanente com ACSs das equipes da ESF, em parceria com a Secretaria Municipal de Saúde (SMS) daquele município desde o ano 2000. Emprega-se essa abordagem teórico-metodológica no tratamento de várias temáticas conectadas entre si: cidadania, direitos humanos e políticas públicas; participação popular e controle social; família e violência doméstica, dentre outras. Todas as temáticas são transversalizadas pela categoria gênero.

Como estão interligadas à prática profissional dos/as agentes de saúde, elas facilitam o processo de aprendizagem, pois as pessoas, em sua realidade, vivenciam o cotidiano como experiência e não como temas ou categorias compartimentalizadas. Por isso, é de extrema importância no processo educativo conhecer o que as pessoas sabem, pensam, sentem e vivem em relação aos 
temas que serão abordados. Tal perspectiva vai ao encontro das indicações de Weitzman (2008), ao afirmar que é importante pensar em técnicas participativas que possam vir a facilitar as diversas formas de expressão, nas quais as pessoas possam ver, ouvir, sentir e pensar, exatamente para que possa haver a reflexão crítica sobre os problemas vivenciados na comunidade, sobre as relações pessoais estabelecidas, os conflitos e a possível mudança de práticas cotidianas.

Em 2011, o NIEG/UFV realizou, em parceria com a SMS, um curso, com duração de quatro semanas, envolvendo 125 profissionais das 15 equipes da ESF de Viçosa, divididos em duas turmas. Considerando o histórico de atividades e pesquisas do NIEG/UFV que envolveram os/as ACSs, apresentamos neste texto ponderações sobre o uso de metodologias participativas na formação permanente de ACSs, numa discussão sobre os limites e as potencialidades de tais metodologias estimularem reflexões e possíveis mudanças nas práticas cotidianas desses profissionais.

Podemos citar como fator de grande contribuição ao desenvolvimento da pesquisa o fato de a primeira autora deste trabalho ter exercido, ainda que em outro município, a profissão de agente comunitária de saúde durante dois anos. Percebemos que essa experiência se mostrou positiva para realizar tal pesquisa, pois possibilitou adentrar no mesmo mundo dos/as ACSs com argumentos para o diálogo e troca de vivências. Essa experiência no setor da saúde permitiu durante as caminhadas transversais e entrevistas um maior contato com os/as ACSs, pois a partir do momento em que se compartilhou a mesma vivência e se demonstrou entendimento sobre as dificuldades na realização do trabalho, os/as agentes se mostraram mais abertos para dialogar sobre os entraves, conflitos e problemas que perpassam a profissão.

\section{Relato do curso de formação para as equipes da ESF}

No final de 2010, as equipes de saúde da ESF de Viçosa passaram por um processo de reestruturação, culminando na contratação de vários novos profissionais. Tal processo é decorrente do procedimento de contratação municipal desses profissionais, que não gera vínculo permanente. Assim, são necessários frequentes processos seletivos para renovar o contrato de trabalho. Em 2011, foi aprovada a lei municipal n. 2.112/2011, que exigia como requisito para o exercício do cargo de ACS "a conclusão de curso de formação inicial e continuada" (Viçosa, 2011). Entre maio e junho de 2011, o NIEG/UFV elaborou e ministrou, em parceria com a SMS de Viçosa, um curso de formação para os/as profissionais do ESF, que contou com a presença de 125 profissionais de saúde do município. 
Por solicitação da SMS, a base do curso seguiu a estrutura curricular proposta pela Escola de Saúde Pública do Estado de Minas Gerais, que tem realizado a formação de ACSs visando a sua qualificação profissional. A partir dessa matriz curricular se construiu o curso de formação, porém, para atender à especificidade do grupo, foram feitas adaptações, reestruturação de conteúdos e inclusão de temas que se mostraram de extrema importância política e social. O curso se estruturava em seis unidades didáticas: Histórico do SUS, da ESF e da profissão de ACS; Preparando a equipe para o trabalho; Positivando saúde; Refletindo sobre família; Operacionalização do trabalho; e Diversidade no trabalho/Temas transversais). Para cada módulo foram elaboradas de duas a quatro oficinas pedagógicas mediante a utilização de técnicas participativas. Em algumas oficinas, as técnicas consistiram de estratégias de grupos extensionistas - como referenciado em Faria e Ferreira Neto (2006) - tendo sido adaptadas ao contexto do curso.

Em outras oficinas pedagógicas, as técnicas consistiram de estratégias criadas por nossa equipe de trabalho. De qualquer forma, mais do que uma dinâmica de grupo ou uma técnica pedagógica, vivenciou-se a construção de um espaço de educação em que os sujeitos não eram passivos. Assim, definiu-se a metodologia como participativa, por ter dialogado com os conhecimentos e saberes prévios dos/as ACSs, e se baseou no protagonismo deles/as. Como o processo de seleção de ACSs envolvia também a renovação de contratos, muitos/as dos/as participantes já eram ACSs. A metodologia e a escolha das técnicas buscaram centrar o foco na vivência e nas experiências dos agentes que já estavam em exercício.

O conteúdo do curso pode ser dividido em duas partes distintas, mas inseparáveis, sendo uma mais técnica, ligada diretamente ao cotidiano de trabalho e operacionalização das atividades dos/as ACSs, e outra mais cidadã, visando à reflexão social e política dos sujeitos. A seguir são apresentados alguns exemplos das temáticas tratadas e técnicas adotadas para abordagem desses conteúdos.

\section{Abordando a formação técnica}

Na unidade didática "Operacionalização do trabalho" foram tratados, dentre outros temas, as visitas domiciliares e o cadastro das famílias residentes na área de abrangência da unidade de saúde. Na abordagem desse assunto, utilizamos a própria ferramenta de trabalho dos/as ACSs: a ficha de cadastro e acompanhamento das famílias, que foi preenchida por grupos de ACSs, numa simulação de uma visita de cadastro a uma família, em que eventuais dúvidas ou dificuldades eram discutidas e socializadas por todo o grupo. 
Outra oficina relacionada a essa unidade didática abordou o território de atuação da equipe da ESF. Inicialmente, fez-se um debate orientado por textos relacionados ao assunto e, a partir das discussões e interpretações dos/as ACSs, solicitamos que cada equipe elaborasse um mapa sobre sua área de atuação, incorporando vivências, percepções e subjetividades de cada indivíduo ou do grupo. O objetivo foi representar o espaço de trabalho refletindo não apenas sobre seus limites físicos e características geográficas, mas também sobre sua dinâmica social.

A oficina "Construção do calendário de trabalho" foi concebida como estratégia de planejamento das visitas domiciliares, na qual procuramos ampliar o sentido dessa atividade. Cada grupo de ACS propôs temas que considerasse relevante de serem tratados com os/as moradores/as, considerando as especificidades da área de abrangência da equipe.

$\mathrm{Na}$ abordagem da oficina "Trabalho e atribuições das/os profissionais das equipes da ESF", utilizou-se a técnica da construção do/a boneco/a de papel. A partir do contorno do corpo de um/a dos/as ACSs desenhado sobre uma folha de papel, os/as agentes eram estimulados/as a escrever ou desenhar sobre a imagem as atribuições e atividades realizadas em seu cotidiano de trabalho. Posteriormente, eram escritas ou desenhadas as atribuições previstas em lei, seguindo-se um debate a fim de que os agentes refletissem sobre a importância de seu trabalho na equipe de saúde, eventuais conflitos entre as atribuições e formas de superação.

\section{Abordando a formação cidadã}

A abordagem dos conteúdos que priorizaram a reflexão social e política dos sujeitos enfatizou o trabalho em equipe e o tratamento de temáticas sobre relações de gênero, direitos humanos, participação popular e controle social. A seguir, apresentamos alguns exemplos da abordagem desses conteúdos.

A temática "Cidadania, direitos e políticas públicas" foi tratada a partir da construção de um painel no qual, inicialmente, eram listadas as necessidades humanas e os direitos humanos identificados pelos/as ACSs em elementos expressos em letras de músicas sobre esses temas. A discussão do painel era feita de forma a estimular a reflexão sobre a existência de necessidades básicas e prioritárias, de como tais necessidades puderam/podem ser garantidas e perpetradas, além da atuação dos sujeitos (como indivíduos ou profissionais) nesse processo e dos deveres dos cidadãos/ãs.

Na atividade "Refletindo sobre saúde", desenvolvida com a técnica da tempestade de ideias, os/as cursistas escreviam em tarjetas o primeiro termo que lhes vinha à cabeça quando escutavam a palavra 'saúde'. As tarjetas eram afixadas em painel, a fim de orientar a construção coletiva de um con- 
ceito positivo de saúde, problematizando a complexidade, diversidade e dinamicidade desse conceito.

Na abordagem do tema "Prevenção de doença e promoção da saúde", utilizamos uma técnica concebida pelo grupo, que denominamos 'técnica do balaio'. No balaio, foram incluídas imagens diversas que faziam alusão à prevenção de doenças e à promoção da saúde. Os/as ACSs eram estimulados a retirar uma das imagens do balaio e a refletir sobre ela, tendo como referência o que entendiam sobre prevenção e promoção e o painel construído na atividade "Refletindo sobre saúde". O debate era conduzido de forma a problematizar os conceitos e a reflexão sobre responsabilidades na 'prevenção de doenças' e 'promoção da saúde'.

Partindo da concepção de organização do trabalho da ESF, que tem a família como unidade de cuidado, elaboramos a unidade didática "Refletindo sobre família". O objetivo era não apenas refletir sobre a necessidade de abordagem da família como um todo, e não apenas o indivíduo doente, mas também problematizar os diferentes tipos de arranjos familiares existentes, comparando-os aos modelos tradicionais e tidos como únicos. Assim, elaboramos dentro dessa unidade a atividade 'Arranjos familiares', solicitando aos/as cursistas que desenhassem em folhas brancas a representação de uma família. Logo após, solicitava-se que desenhassem a sua família e, a seguir, que fizessem o desenho de um arranjo familiar diferente do que já haviam representado.

A última unidade didática trabalhada tratou da "Diversidade no trabalho/Temas transversais". A primeira atividade dessa unidade, 'Refletindo sobre sexo e gênero', objetivou estimular a reflexão sobre a naturalização da produção de desigualdades sociais e de gênero a partir das diferenças biológicas entre homens e mulheres. A técnica empregada foi o videodebate, após a projeção do filme Gênero, mentiras \& videotape, dirigido por Lucila Meirelles, produzido em 1995 (Gênero..., 1995).

Finalmente, a atividade "Enfrentando a violência de gênero" foi conduzida a partir da apresentação de uma peça teatral baseada no material formativo, elaborado pelo NIEG/UFV, Rede protetiva de enfrentamento à violência contra as mulheres: casa das mulheres" (Núcleo Interdisciplinar..., 2011), no qual são problematizados o ciclo da violência doméstica e os tipos de violência contra a mulher e apresentado o trabalho da rede não especializada de enfrentamento da violência doméstica em Viçosa.

\section{Caminho investigativo da pesquisa}

Para refletir sobre o uso de metodologias participativas na EPS de ACSs, valemo-nos da análise de 12 relatorias construídas a partir da realização de 12 
caminhadas transversais em cinco unidades de saúde e da análise de cinco entrevistas com ACSs de três equipes de saúde do município de Viçosa. As caminhadas transversais e as entrevistas foram efetuadas alguns meses após o término do curso de formação.

A entrevista semiestruturada, segundo Alberti (2004), consiste em uma ação interativa, que se aproxima de um diálogo, foca determinados assuntos, é adaptável e flexível, baseia-se num roteiro, enfim, são esses pontos que a distinguem de uma entrevista comum. Essa entrevista incluiu perguntas fechadas e abertas, possibilitando, em nosso caso específico, que o/a ACS pudesse falar sobre a temática proposta, o que favoreceu a interação entre as duas partes envolvidas. Segundo Boni e Quaresma (2005, p. 75), “este tipo de entrevista colabora muito na investigação dos aspectos afetivos e valorativos dos informantes que determinam significados pessoais de suas atitudes e comportamentos". Foram realizadas cinco entrevistas com agentes comunitários/as de três unidades de saúde do município, a fim de compreender a prática profissional desses ACSs e possíveis mudanças influenciadas pelo curso de formação com base nas técnicas participativas.

Outra técnica utilizada foi a caminhada transversal que, segundo Alencar e Gomes (apud Jardim e Pereira, 2009), consiste em percorrer um determinado trecho do bairro ou comunidade acompanhado de um informante local. Ao realizar a caminhada, é preciso estar atento aos detalhes referentes à paisagem, problemas locais, realidade, enfim, a todo o contexto local, de modo a facilitar o entendimento de questões que o pesquisador está buscando compreender. Realizaram-se 12 caminhadas transversais, acompanhadas por 12 agentes de saúde de cinco equipes da ESF de Viçosa. Durante as caminhadas, observaram-se aspectos relativos ao cotidiano da prática de trabalho dos/as ACSs, as relações estabelecidas com os/as usuários/as, bem como a prática profissional dos/as ACSs, verificando-se se houve apropriação dos temas discutidos durante o processo de formação e como isso aparece no cotidiano. Ao término de cada caminhada construíram-se relatorias que se tornaram material de análise.

No exame minucioso das entrevistas e das relatorias, percebemos grande destaque em duas temáticas específicas, as quais, por esse motivo, foram selecionadas para discussão e aprofundamento neste artigo. São elas "Prevenção da doença e promoção da saúde" e "Violência de gênero", a primeira relacionada aos conteúdos técnicos do trabalho dos/as ACS, e a segunda voltada para a formação do sujeito.

Destacamos que as pesquisadoras que realizaram as caminhadas transversais e as entrevistas são as mesmas que elaboraram e ministraram as oficinas formativas. Essas pesquisadoras integravam a equipe do projeto e participaram de todo o processo formativo, desde a elaboração/construção até a realização. 
Informamos também que o projeto "Educação permanente em saúde e a Estratégia Saúde da Família: instrumentalização para a prática reflexiva", financiado pela Fundação de Amparo à Pesquisa do Estado de Minas Gerais (Fapemig), edital n. 09/2010, Processo CDS - APQ - 03234-10, foi submetido ao Comitê de Ética em Pesquisa com Seres Humanos da Universidade Federal de Viçosa e aprovado, conforme ofício n. 200/2011. A participação no estudo foi voluntária, e os/as participantes da leitura assinaram o termo de consentimento livre e esclarecido.

\section{ESF e a operacionalização dos conceitos de prevenção de doença e promoção da saúde}

Em diferentes temas abordados no curso de formação discutiram-se questões relacionadas ao cotidiano de trabalho e ao exercício da profissão de ACS. Nesses momentos, procuramos destacar e reforçar os aspectos positivos e inovadores das experiências de reorientação do modelo assistencial hospitalocêntrico, medicalizante e verticalizado, que resultaram em práticas descentralizadas, de estímulo à atenção primária. Tais experiências se caracterizam por buscar incluir os sujeitos no seu contexto social e afetivo, a exemplo do que fundamentam os princípios da ESF.

Com base no que foi trabalhado na atividade que teve como tema a "Prevenção da doença e promoção da saúde", em que foi utilizada a técnica de dinâmica de grupo 'balaio da saúde', os/as ACSs puderam perceber que os elementos que envolvem a qualidade de vida e a satisfação pessoal também são determinantes no processo saúde-doença. Conforme proposto por Leavell e Clarck (apud Czeresnia, 2003, p. 45), "prevenir em saúde exige uma ação antecipada, baseada no conhecimento da história natural, a fim de tornar possível o progresso posterior da doença". As ações preventivas definem-se como intervenções orientadas para evitar o surgimento de doenças específicas, reduzindo sua incidência e prevalência nas populações. Já o conceito de promoção em saúde se define, tradicionalmente, de maneira bem mais ampla do que o de prevenção, pois "se refere a medidas que não se dirigem a uma determinada doença ou desordem, mas servem para aumentar a saúde e o bem-estar gerais"' (Leavell e Clarck apud Czeresnia, 2003, p. 45).

Embora os profissionais tenham demonstrado compreensão e fizessem distinção entre os conceitos de 'prevenção de doenças' e 'promoção da saúde', a operacionalização de ambos está ainda restrita no cotidiano do trabalho e enfrenta diferentes desafios, conforme pode ser observado no relato de uma agente comunitária acompanhada durante a caminhada transversal: 
Eu me lembro da parte da abordagem do paciente, como é que você entra num contexto familiar, ir à parte de como você trabalha na promoção da saúde. Só que na cabeça do brasileiro não tá na promoção, está na cura; se você não sai do consultório com uma receita na mão, o médico não vale nada! Então, assim, o teórico que vocês elaboraram, que é o que o governo fala do que é o agente comunitário, a forma que ele deve trabalhar, isso não comporta a realidade do brasileiro. Por que eu já andei até lendo o negócio [atribuições] dos ACSs, que a metodologia agora é que o agente tem que ajudar a comunidade a ter consciência, a fazer as coisas pra prevenir a doença, pra promover a saúde, pra não deixar a doença chegar pra ter que tratar. Só que a realidade do Brasil hoje em dia é tratamento da doença, ainda é a cura, a medicação. Isso é muito por causa da nossa cultura (ACS, mulher).

A partir da fala da agente de saúde, percebemos que, apesar de a política de atenção primária ter avançado em relação ao exercício profissional, valorizando e estimulando a prática humanizada e o olhar holístico sobre o indivíduo, isso ainda não conseguiu efetividade o suficiente para mudar, pelo menos de modo mais abrangente, a expectativa da população, ainda bastante centrada no modelo hospitalocêntrico, tecnicista e pautado na cura de doenças por meio de medicação. Ou seja, os processos de transformação e ressignificação das práticas de atenção em saúde, além de serem vivenciados de formas diferentes, encontram-se em momentos distintos. Se, para a profissional, a necessidade de mudança é clara e premente, o/a usuário/a ainda não percebe a desatualização do modelo tradicional de atenção à saúde, mesmo porque a experiência da doença faz com que a população seja dependente desse modelo, retroalimentando as estruturas e sistemas que o reforçam e o mantêm prevalecente.

Nesse palco conflituoso, em que diferentes subjetividades e expectativas se encontram, as dificuldades de operacionalização dos conceitos de prevenção e promoção aparecem, uma vez que os/as usuários/as contam com os/as ACSs para resolver seus problemas imediatos de saúde. Como a prática em saúde é uma ação dialógica, ainda que o profissional tenha consciência da necessidade de mudança, executar a mudança não pode ser responsabilidade de um dos atores apenas.

Embora o/a ACS tente orientar sua prática profissional positivando o conceito de saúde e, por vezes, priorizando ações de promoção da saúde no contato com o/a usuário/a, ainda é estratégia importante para os/as ACSs falar ou abordar a doença nas visitas domiciliares, pois é uma forma de legitimar sua entrada nas residências e de construir vínculo.

Um dos entraves, então, que torna ainda mais complexa a reorientação da atenção à saúde, priorizando ações de promoção, é a dificuldade de desconstruir conceitos culturais prevalecentes, como explicitado na fala da 
ACS, onde o/a usuário/a ainda tem a expectativa do tratamento e acompanhamento por meio de medicamentos. Isso acaba fragmentando o sujeito e visando apenas a doença, fora do contexto em que se manifestou.

No decorrer da caminhada transversal, pudemos perceber que, durante as visitas domiciliares, as atividades realizadas pelos/as ACSs envolveram a entrega de exames preventivos para mulheres e marcação de novos exames; a informação sobre marcação de consultas na unidade de saúde e a conferência de cartões de vacinação das crianças, ou seja, atividades centradas na prevenção de doenças e agravos.

Durante as oficinas do curso de formação, procurou-se demonstrar o papel político dos/as agentes de saúde como mobilizadores sociais e educadores populares, sendo sua ação muito mais ampla do que averiguar exames e medicamentos.

Assim, avaliamos que o curso cumpriu o objetivo de possibilitar a apropriação dos conceitos e dos princípios de uma proposição crítica ao modelo de atendimento à saúde. Entretanto, o exercício efetivo desses conceitos e princípios no cotidiano não foi totalmente alcançado. Há uma insuficiência em criar alternativas no contato com o/a usuário/a que permita a desconstrução efetiva do modelo curativo. Além disso, apesar de os/as ACSs continuarem a reproduzir o modelo hegemônico de atenção em que tratamento e reabilitação ainda são vistos como prioritários, indicamos que tal descompasso também decorre da complexidade de ações/atores que envolvem a promoção da saúde. Ou seja, essa mudança não pode ser focada na individualização das ações, que, no caso, se refere à intervenção dos/as ACSs, isolando-os/as no processo de reformulação da saúde.

Conforme Gutierrez,

para a promoção da saúde, o objetivo contínuo é um nível ótimo de vida e de saúde; portanto, a ausência de doenças não é suficiente, sempre algo deverá ser feito para promover um nível de saúde melhor e condições de vida mais satisfatórias (Gutierrez apud Buss, 2003, p. 33).

Assim, dada a amplitude do conceito de promoção da saúde, sua real efetivação não requer nem depende apenas de mudanças nas práticas de atenção à saúde, mas de uma ação conjunta que envolva diferentes setores, instituições e organizações que direta ou indiretamente participam ou são responsáveis por serviços e ações que impactam as condições de vida da população. Esse envolvimento não significa meramente uma atuação dos diferentes setores em seus domínios específicos em prol de um objetivo único, mas uma necessária redefinição de prioridades e reordenamento das práticas com o imperativo de se efetivar a ação interdisciplinar, a fim de se dar conta de todos os aspectos que são considerados, atualmente, determinantes 
da saúde. Tal reordenamento não pode ser focalizado apenas no exercício cotidiano do trabalho dos/as agentes de saúde.

O modelo hospitalocêntrico de valorização da atenção à saúde enquanto prática curativa também acaba por influenciar a abordagem a 'estado de não doença'. Como exemplo dessa situação, citamos o atendimento realizado a mulheres. Na maioria das vezes, a abordagem é voltada para assuntos relacionados ao cuidado com os filhos, prevenção e tratamento dos principais agravos ginecológicos e para o planejamento familiar. Sobre esse último, percebemos que a prioridade da atenção é dada às mulheres, uma vez que são consideradas responsáveis pela reprodução. Para ilustrar melhor a discussão, apresentamos a seguir a fala de uma das ACSs durante a caminhada transversal:

O índice de gravidez adolescente é muito alto. Ando com preservativos e anticoncepcionais na bolsa. Outro dia, durante minha visita, parei em três casas onde meninas de 14, 16 anos estavam grávidas. Numa dessas casas, a menina tinha retardamento mental e acabava de abortar. Aí, parei com ela e sua mãe e perguntei se ela estava seguindo as orientações do médico. A moça respondeu que não entendeu o que ele falou para ela fazer, me mostrou a receita com as orientações. Li e expliquei como a menina devia tomar o anticoncepcional dizendo que se ela, ainda assim, tiver dúvida que no dia seguinte eu voltaria com uma cartela para demonstrar (ACS, mulher).

A fala da ACS evidencia a marca do discurso hegemônico de gênero, na medida em que a abordagem no que diz respeito à saúde dos filhos e aos métodos contraceptivos se direciona exclusivamente para a mulher, reforçando a desigualdade de gênero ainda tão marcante em nossa sociedade. A compreensão da importância do discurso técnico/médico como mediador da manutenção das condições de desigualdades entre gênero é importante para a efetivação da proposta da ESF como reprodutora dos princípios do SUS de integralidade, igualdade e equidade. Por seu turno, a superação da perspectiva de que as mulheres são as responsáveis pela reprodução também implica a superação/revisão dos modelos tradicionais de abordagem da temática do planejamento familiar, fazendo com que a ação possa ir além da distribuição de contraceptivos.

\section{O teatro como instrumento de reflexão sobre a violência de gênero}

Outra temática abordada no curso de formação foi a "Violência de gênero". Conforme já citado, realizou-se uma peça, encenada por integrantes/bolsistas do NIEG/UFV, cuja proposta era representar o ciclo da violência, enfatizar os tipos de violência contra as mulheres e apresentar as instituições 
componentes da rede protetiva de atendimento à mulher em situação de violência existente em Viçosa.

De acordo com Taquette et al. (2007), o setor da saúde até pouco tempo avaliava a violência contra a mulher como um fenômeno de responsabilidade apenas do poder judiciário, mesmo quando essa violência causava danos físicos. Mas, hoje, esse fenômeno é visto como de importância e interesse social, cabendo a diversos setores da sociedade a realização de ações pautadas para sua eliminação e assistência às mulheres em situação de violência.

Para tanto, os/as profissionais da saúde precisam de capacitação/preparação para lidar com esse tipo de situação, a fim de saber acolher a mulher e encaminhá-la para outras instituições e serviços que atuem no enfrentamento de violência, realizando o acolhimento e acompanhamento. Segundo Taquette (2007, p. 14), “o envolvimento destes profissionais, de forma competente e integrada com os outros setores da sociedade, poderá levar a um impacto positivo na saúde desta população".

Essa temática foi muito impactante, uma vez que, durante a realização da oficina, tivemos desde depoimentos pessoais de histórias de violência vivenciadas pelas próprias agentes, como também manifestações de revolta. Os resultados alcançados a partir do uso do teatro seguido de debate são sutis, e a percepção da mudança de atitude frente a tal situação está acontecendo gradativamente.

Em uma das entrevistas, a ACS fala do tema da violência contra as mulheres, dizendo que a abordagem no curso ajudou a pensar a prática humanizada em saúde, pois relata que, no bairro onde trabalha, acontecem muitos casos de agressão a mulheres. Ela afirma que

tem vários casos de violência, e depois disso eu não sei se a gente mudou o jeito de tratar, muitas pessoas começaram a se abrir, entendeu? A violência contra a mulher, por exemplo, aí muitas pessoas começaram a se abrir, outras a gente sabe do caso, às vezes a vizinha comenta ou a pessoa, você percebe ali quando a pessoa fala. Eu comecei a fazer até algumas fichas de notificação, mas elas tomam um certo tempo, aí eu já tô fazendo umas pra passar pra chefe pra ela poder... entendeu? (ACS, mulher).

Antes da capacitação pelo NIEG, eu desconhecia alguns tipos de violência, como a psicológica. Após o curso fui entender que existem vários tipos de violência, como a patrimonial, a moral, não é só a física. Depois da capacitação, fiz quatro notificações de violência doméstica contra a mulher, uma delas, inclusive, foi a minha (ACS, mulher).

Quando se trabalha com educação permanente e metodologias participativas, estimula-se a reflexão sobre as práticas cotidianas. Nesse momento, 
a ACS, além de perceber que a notificação compulsória dos casos de violência se mostra como uma responsabilidade social e que faz parte de suas atribuições como profissional da saúde, também se apresenta como vítima da mesma situação no momento em que preenche sua própria ficha de notificação. A agente de saúde disse saber da importância de notificação dos casos de violência, mas que mesmo ciente de que a notificação é sigilosa, afirma ficar um pouco receosa. Isso evidencia que a compreensão não passa apenas pelos processos racionalizados sobre a realidade, mas envolve dimensões afetivas muito arraigadas nas experiências dos sujeitos.

Percebemos a importância que os/as ACSs deram à abordagem dessa temática e à forma como foi trabalhada, ou seja, a apresentação do teatro sobre o ciclo da violência. Essa fala pode ser justificada quando, em entrevista, foi perguntado a um ACS (homem) sobre qual temática abordada no curso mais chamou sua atenção e qual técnica utilizada ele mais se recordava. A resposta foi a seguinte:

Um dos temas, assim, que eu me lembro é sobre a... no caso, a violência dentro de casa... do ambiente da própria família, dentro da residência, no caso da agressão contra a mulher, da violência contra a mulher. Eu acho que foi um tema importante que esclareceu muito pra mim; no meu caso, como agente de saúde, tinham muitas coisas que eu desconhecia. Foi importante pra me orientar nos conhecimentos. Eu acho que foi importante, interessante a forma como foi abordado, porque, assim, eu mesmo não tinha tanto conhecimento sobre essa lei [Lei Maria da Penha] e acho que nem todo mundo tem conhecimento sobre essa lei (ACS, homem).

A partir dessa fala, percebemos o quão importante foi trabalhar essa temática utilizando técnicas participativas, pois o teatro, os debates, a troca de experiências e as informações são o que realmente contribuem para o questionamento e a reorganização da forma de pensar sobre vários assuntos que estão incorporados no cotidiano e que visam à percepção e à reflexão para a prática profissional, e não exatamente para uma mudança de pensamento e comportamento.

Como bem lembra Dias (2007, p. 3), “educar para os direitos humanos, prescinde, então de uma escuta sensível e de uma ação compartilhada entre professores e alunos, capaz de desencadear processos autônomos de produção de conhecimento". Ou seja, o uso das metodologias participativas não consiste em ensinar e sim estimular o desenvolvimento da reflexão crítica e o estímulo à criatividade e iniciativa. Esse processo é construtivo, a pessoa pensa, entende e aplica o conhecimento. Ainda, segundo Ribeiro e Motta (1996), o uso das metodologias participativas permite que todos/as compartilhem da construção coletiva de conhecimento, dando abertura às 
diferentes formas de expressão dos conhecimentos prévios e contemplando as diversas formas e tempos de aprendizagem dos/as participantes.

O teatro, dessa forma, mostrou-se como uma das múltiplas linguagens existentes, que nem sempre são evidentes, mas que possuem como característica promover situações que possam ser significativas e a reflexão. Percebemos, assim, a importância da temática "Violência de gênero" ter sido incluída nesse curso de formação, em que objetivávamos provocar a reflexão dos/as ACSs acerca dos tipos de violência existentes e a rede protetiva de enfrentamento à violência contra as mulheres existente em Viçosa. Acreditamos que alcançamos nosso objetivo, pois, através das falas, pudemos resgatar desde depoimentos de casos acontecidos no momento das visitas domiciliares até depoimentos pessoais. São nesses momentos que acontecem a reflexão crítica e a apreensão e construção de novos conhecimentos e, mais ainda, podemos dizer que a técnica do teatro se mostrou apropriada para realizar esse tipo de abordagem, pois o teatro nos comove, possibilita nos colocarmos no lugar do outro e refletirmos sobre situações que não seriam facilmente perceptíveis se a forma de abordagem fosse outra qualquer.

\section{Considerações finais}

A experiência do curso de formação estimulou a reflexão por parte dos/as profissionais, em especial os/as agentes de saúde, em direção a uma possível mudança de suas práticas cotidianas, na qual se perceberam como cidadãos/ãs em constante processo de formação.

A análise do potencial das metodologias participativas utilizadas nesse curso de formação nos permitiu perceber que houve empoderamento dos/as ACSs acerca dos temas abordados, podendo ser entendidos como construtores/as de vínculo entre equipe de saúde e comunidade, papel fundante da proposta de atuação da ESF. Não podemos dizer que o recurso das metodologias participativas 'transformou' os/as ACSs em sujeitos reflexivos, gerando, assim, automaticamente, a mudança de pensamento, nem medir o impacto que essa metodologia tem no processo de construção do pensamento reflexivo. Muito menos é possível afirmar que, a partir do curso de formação, os/as ACS modificaram suas práticas de trabalho. Porém, podemos ressaltar que as técnicas participativas empregadas durante o curso se mostraram muito favoráveis à realização desse trabalho por estimularem a reflexão sobre o cotidiano profissional.

Gostaríamos de concluir este artigo indicando que entendemos que o próprio processo de construção do curso se deu de forma participativa e dialógica, em que várias pessoas estiveram envolvidas na proposta de elaboração do mesmo. Como solicitado pela SMS, a base do curso seguiu a estrutura curricular proferida pela Escola de Saúde Pública do Estado de Minas 
Gerais, mas como a prática é vivenciada de diferentes maneiras e cada ACS entende seu cotidiano de trabalho utilizando uma lente específica, nossa equipe precisou entender a prática desses agentes de saúde, as questões que permeiam a profissão, os temas que estão diretamente inseridos no cotidiano de trabalho que não estão contemplados nessa matriz curricular, mas que deveriam de alguma forma ser abordados. Então, houve um trabalho conjunto na construção de um curso que pudesse abranger, além de atribuições e conteúdos técnicos, temas visando à reflexão sobre questões de interesse político e social. A construção desse curso de formação se deu a partir da interação de diferentes vozes (ACSs, pesquisadores do NIEG/UFV, ex-agente comunitária de saúde, SMS), o que possibilitou, tanto durante a sua preparação quanto na sua execução, a construção coletiva do saber.

Compreendemos que o processo participativo ocorre muito antes do momento em que o curso é realizado, quando se utilizam técnicas específicas; ele se dá a partir do instante em que é idealizado, pois é nesse momento que acontece a dinâmica entre as partes envolvidas na elaboração de uma proposta participativa que atenda às especificidades do grupo. Portanto, o processo participativo se dá em todos os momentos, desde o planejamento, ou seja, o 'pensar o curso', pensar a metodologia a ser empregada até a sua execução, sempre visando à construção coletiva do saber, seja para quem elabora, seja para quem participa.

Ainda que não tenha sido objeto específico de reflexão deste trabalho, também indicamos que a experiência do curso de formação contribuiu para maior integração da equipe, na medida em que as atividades eram desenvolvidas, quase sempre, considerando a formação das equipes de saúde. Além disso, em vários momentos, observamos que a equipe procurava refletir sobre as temáticas, resgatando experiências do grupo e vivências da prática profissional dos contextos específicos de seus trabalhos, o que, por sua vez, também foi potencializado pelo uso de metodologias participativas.

\section{Colaboradores}

Natália Hosana Nunes Rocha participou da concepção do estudo, planejamento do trabalho, construção e análise dos dados, elaboração e revisão do manuscrito. Paula Dias Bevilacqua e Marisa Barletto conceberam o estudo e participaram do planejamento do trabalho, análise dos dados, elaboração e revisão do manuscrito. Informamos que não há conflitos de interesse. 


\section{Agradecimentos}

Os/as autores/as agradecem o apoio financeiro e as bolsas de apoio técnico à pesquisa e iniciação científica recebidos da Fapemig; à SMS da Prefeitura Municipal de Viçosa e às equipes de saúde da família do município pela parceria na condução do trabalho.

Resumen En este texto se busca reflexionar sobre el uso de metodologías participativas en la educación permanente de agentes comunitarios de salud, en una discusión sobre los límites y potencialidades para que tales metodologías estimulen reflexiones y posibles cambios en las prácticas cotidianas de estos profesionales. Se realizaron entrevistas y recorridos transversales con los agentes, que resultaron en relatos utilizados como material de análisis. No sería simple medir el impacto que esta metodología tiene en el proceso de construcción del pensamiento reflexivo, pero el análisis del potencial de las metodologías participativas en actividades de formación de agentes comunitarios de la salud permitió percibir que hubo un empoderamiento en cuanto a los temas abordados. Se pudo comprender cuán significativas se han mostrado las metodologías en el enfoque de las temáticas, especialmente en los temas "prevención de enfermedades y promoción de la salud" y "violencia de género". Se concluye que el hecho de que algo pueda ser percibido con otros significados y sentidos permite otros modos de producción de prácticas cotidianas.

Palabras clave construcción colectiva; conocimiento y práctica; actuación profesional.

\section{Notas}

1 Universidade Federal de Viçosa, Departamento de Educação, Viçosa, Minas Gerais, Brasil.

$<$ natalia.rocha@ufv.br>

Correspondência: Rua Santa Luzia, 115, apto. 501, Centro, CEP 36570-000, Viçosa, Minas Gerais, Brasil.

2 Universidade Federal de Viçosa, Departamento de Veterinária, Viçosa, Minas Gerais, Brasil.

<paula@ufv.br>

3 Universidade Federal de Viçosa, Departamento de Educação, Viçosa, Minas Gerais, Brasil.

<barletto@ufv.br> 


\section{Referências}

ALBERTI, Verena. Ouvir e contar: textos em história oral. Rio de Janeiro: Editora FGV, 2004.

BONI, Valdete; QUARESMA, Sílvia. Aprendendo a entrevistar: como fazer entrevistas em Ciências Sociais. Em Tese: Revista Eletrônica dos Pós-Graduandos em Sociologia Política da UFSC, v. 2, n. 3, p. 68-80, 2005.

BRASIL. Ministério da Saúde. Secretaria de Atenção à Saúde, Política Nacional de Humanização da Atenção e Gestão do SUS. $O$ HumanizaSUS na atenção básica. Brasília, DF: Ministério da Saúde, 2009. 40 p.

BUSS, Paulo M. Uma introdução ao conceito de promoção da saúde. In: CZERESNIA, Dina; FREITAS, Carlos M. (org.). Promoção da saúde: conceitos, reflexões, tendências. Rio de Janeiro: Editora Fiocruz, 2003. p. 15-38.

CECCIM, Ricardo B. Educação permanente em saúde: descentralização e disseminação de capacidade pedagógica na saúde. Ciência \& Saúde Coletiva, Rio de Janeiro, v. 10, n. 4, p. 975-986, 2005.

CZERESNIA, Dina. O conceito de saúde e a diferença entre prevenção e promoção. In: CZERESNIA, Dina; FREITAS, Carlos M. (org.). Promoção da saúde: conceitos, reflexões, tendências. Rio de Janeiro: Editora Fiocruz, 2003. p. 39-52.

DE CASTRO DIAS, Leda M. et al. A educação permanente como instrumento de transformação nas práticas do assistir/cuidar da enfermagem. Revista Enfermería Global, Murcia, v. 6, n.10, p. 1-8, maio-2007.

DIAS, Adelaide A. Da educação como direito humano aos direitos humanos como princípio educativo. In: SILVEIRA, Rosa M. G. et al. (org.). Educação em direitos humanos: fundamentos teórico-metodológicos. João Pessoa: Editora Universitária/UFPB, 2007. p. 441-456,

ESCOREL, Sarah et al. O Programa de Saúde da Família e a construção de um novo mo- delo para a atenção básica no Brasil. Revista Panamericana de Salud Pública, Washington, v. 21, n. 2-3, p. 164-176, 2007.

FARIA, Andréa A.; FERREIRA NETO, Paulo S. Ferramentas do diálogo - qualificando o uso das técnicas do DRP: diagnóstico rural participativo. Brasília: MMA; IEB, 2006.

GÊNERO, mentiras \& videotape. Direção de Lucila Meirelles. São Paulo: Instituto Cajamar e TVT Produções, 1995. Vídeo, 18 min. color.

JARDIM, Anna C. S.; PEREIRA, Viviane S. Metodologia qualitativa: é possível adequar as técnicas de coleta de dados aos contextos vividos em campo? In: CONGRESSO SOCIEDADE BRASILEIRA DE ECONOMIA, ADMINISTRAÇÃO E SOCIOLOGIA RURAL, 47., 2009, Porto Alegre, Anais... Brasília: SOBER, 2009. Disponível em: <www.sober. org.br/palestra/13/392.pdf>. Acesso em: 14 mar. 2013.

MANCIA, Joel R.; CABRAL, Leila C.; KOERICH, Magda S. Educação permanente no contexto da enfermagem e na saúde. Revista Brasileira de Enfermagem, Brasília, DF, v. 57, n. 5, p. 605-610, 2004.

NÚCLEO INTERDISCIPLINAR E ESTUDOS DE GÊNERO (NIEG). Rede protetiva às mulheres em situação de violência. Viçosa: Universidade Federal de Viçosa. 2011. 34p. Disponível em: <www.nieg.ufv.br/wp-content/ uploads/Cartilha-Rede-Protetiva.pdf $>$. Acesso em: 5 fev. 2013.

RIBEIRO, Eliana C. O.; MOTTA, José I. J. Educação permanente como estratégia na reorganização dos serviços de saúde. 1996. Disponível em: <www.saude.ms.gov.br/controle/ShowFile. php?id=26239> . Acesso em: 8 jan. 2012.

TAQUETTE, Stella et al. Mulher adolescente/jovem em situação de violência: propostas de intervenção para o setor saúde módulo de autoaprendizagem. Brasília, DF: Secre- 
taria Especial de Políticas para as Mulheres, 2007. 128 p.

VIÇOSA. Lei municipal n. 2.112, de 18 de março de 2011. Dispõe sobre a criação dos cargos públicos de Agente Comunitário de Saúde e de Agente de Combate às Endemias e dá outras providências. Disponível em: $<$ www.vicosa.mg.leg.br/legislacao/leismunicipais/2011/LEI\%20No\%202.112.pdf>. Acesso em: 2 dez. 2012.
WEITZMAN, Rodica. Educação popular em segurança alimentar e nutricional: uma metodologia de formação com enfoque de gênero. Belo Horizonte: Rede de Intercâmbio de Tecnologias Alternativas, 2008. 232 p.

Recebido em 16/08/2013

Aprovado em 30/06/2014 